\title{
Present situation and Countermeasures of Shanghai City disposal of restaurant kitchen garbage
}

\author{
Zhiqiang $\mathrm{Yu}^{1}$, Weidong $\mathrm{Xu}^{2}$, Chenjie Zhu ${ }^{2}$, Shuai Shi ${ }^{2}$, Ying $\mathrm{Chen}^{3}$
}

1. Center of Materials Science and Quality Testing, Shanghai Institute of Measurement and Testing Technology, Shanghai 200233, China

2. Test Laboratory of Security and Crime Prevention and Information Security Products and

SYstems, Third Institute of the Ministry of Public Security, Shanghai 200031, China

3. Automation Engineering Department, Shanghai Marine Diesel Engine Research Institute, Shanghai 201108, China

Email: yuzhiqiang@simt.com.cn

Keywords: kitchen waste; resource; management

Abstract. This paper introduces the situation of waste characteristics and kitchen kitchen garbage disposal in Shanghai City, analyses the existing problems in processing status, expounds the kitchen garbage resource recycling technology and the prospects for development, to provide suggestions for the future of Shanghai food waste management and recycling.

\section{Introduction}

Kitchen waste is an important part of municipal solid waste. According to data in Overview of Disposal of Domestic and Foreign Kitchen Waste issued by Environmental Engineering School of Tianjin University and research institutions of Tianjin Drainage Management Office, domestic kitchen waste accounted for $37 \%-62 \%$ of municipal solid waste. At the same time, with substantial increase of living consumption level of people in recent years, public catering structure and quantity are more abundant. Therefore, the proportion will continue to rise; see Fig. 1.

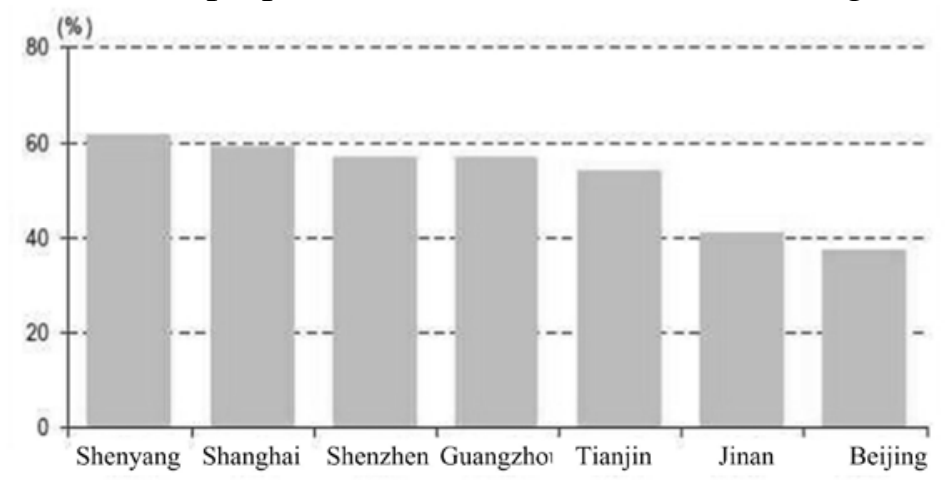

Fig. 1 Proportion of Food Waste in Partial Municipal Solid Waste

According to data of Bureau of Statistics, 37\% of kitchen waste accounted for lower limit; garbage removal capacity of our country in 2011 is about 164 million tons, of which removal capacity of kitchen waste of our country in 2011 is at least 60.66 million tons, converted into more than 160,000 tons per day. The scale is amazing; see Fig. 2. 


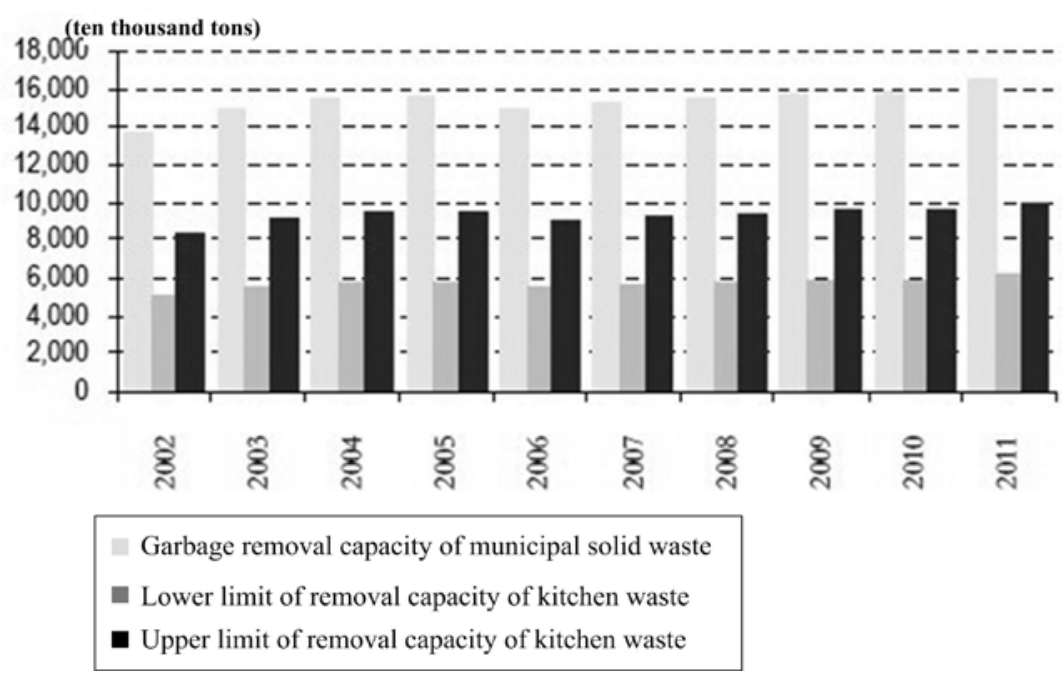

Fig. 2 Total Quantity of Kitchen Waste and Garbage Removal of Our Country in 2002-2011

Current kitchen waste must be formally, effectively and strictly handled because it is of large production, more harmful bacteria, perishable deterioration, breeding all kinds of pests and polluting environment, and it will pollute the soil, air and water, and interfere with the normal life of the public in case of leakage in transport and collection process. Kitchen waste should be classified and collected to be handled and separately transported because of its unique nature. However, disposal of current domestic kitchen waste is not fully incorporated into normative channel; there is disorderly management of kitchen waste disposal in some areas; random disposal will cause harms to people's health and environment.

\section{Current situation of kitchen waste in Shanghai}

According to survey results of Shanghai Tongji University in 2012, daily output of kitchen waste in Shanghai is about 1,400 tons; the highest output is up to 2,000 tons per month, and it shows a rapid upward trend. Test results of main components of kitchen waste in partial organization of Shanghai are shown in Table 1.

\begin{tabular}{|l|l|l|l|l|l|}
\hline Source of kitchen waste & Moisture content \% & Organic matter \% & Crude protein \% & Crude fat \% & Oil content mg/l \\
\hline First-class restaurant & 75.50 & 95.65 & 25.46 & 24.05 & 6810 \\
\hline Middle-class restaurant & 74.35 & 95.85 & 23.25 & 23.65 & 5530 \\
\hline Low-end restaurant & 77.15 & 94.40 & 23.67 & 24.68 & 2596 \\
\hline Organization canteen & 76.45 & 94.88 & 24.85 & 26.47 & 2403 \\
\hline
\end{tabular}

Table 1: Test Results of Main Components of Kitchen Waste in Partial Organization of Shanghai

It can be seen from Table 1 that moisture content of food waste is high, and it is almost higher than or close to $75 \%$; crude fat and crude protein accounts for about $25 \%$; it is of high nutritional value, and the ratio is close to feed for breeding pigs. Higher organic content may be related to dietary habits of the South. Oil content generated in high-class restaurants and middle-class canteens is higher than that in low-end restaurants and canteens, which is mainly due to cooking methods of high-end restaurants and high oil content of vegetable.

\section{Characteristics of kitchen waste in Shanghai}

\subsection{High moisture content}

High moisture content of kitchen waste brings difficulty for transportation, collection and disposal. However, if kitchen waste with high moisture content is burned on site, it is predicted that average calorific value is about $2500 \mathrm{KJ} / \mathrm{kg}$, which is difficult to reach $(5,000 \mathrm{~kJ} / \mathrm{kg}$ or above) 
calorific value required for power generation for incineration, and it is easy to generate toxic and harmful substances such as dioxins after incineration, and landfill will produce a large amount of biogas leachate. The leachate will pollute surface and ground water through runoff permeation and surface and cause secondary pollution to environment.

\subsection{Perishable}

Organic content of kitchen waste in Shanghai is very high and about 95\%, and it is mainly starch, animal fiber and food. If conventional processing method is used, the above characteristics easily lead to quick deterioration of organic matter rich in kitchen waste in high temperature and resulting in Escherichia coli and other pathogenic microorganisms. Therefore, kitchen waste which is directly used to feed pigs may harm human health through food chain.

\subsection{High nutritive value}

In addition to crude fat, crude protein and high organic content, kitchen waste in Shanghai is of high sugar content, and it also contains rich potassium, phosphorus, nitrogen, calcium and various trace elements, and less harmful and toxic chemicals (such as heavy metals, etc.); it is nutrient-rich and complete, and it will be rich resources for production of organic fertilizer and suitable for re-use.

\section{Main problems in disposal of kitchen waste of Shanghai}

4.1 Existing technology and method used for disposing kitchen waste are not scientific

Recycling level of disposal technology of existing kitchen waste is low, and disposal is not complete. Main treatment method of kitchen waste in disposal plant put into operation is anaerobic digestion and priority disposal of industrial grease; part of the kitchen waste is produced to be feed additives; the remaining residue is used to make organic fertilizer. Low processing efficiency, low technical level, long cycle length, incomplete processing and poor working environment are present disposing situation for majority of enterprises.

\subsection{Capacity for handling existing kitchen waste is not enough}

Data report for 2013 shows that each district in Shanghai is of 1-2 kitchen waste disposal station; daily collection quantity of kitchen waste in the whole city is 1,200 tons; it is expected that daily kitchen waste of Shanghai will be higher than 1600 tons/day by 2015; the gap is very large.

\subsection{Channel for collection and transportation is not perfect}

The public lacks adequate awareness of environmental protection and recycling of kitchen waste; in addition to large enterprises, majority of kitchen wastes are classified by the public consciously; truck is used as transportation tool by the rest of merchant; electric vehicles and manpower tricycle are used as transportation tool in suburbs; which are prone to pour and side leakage in transportation process, and affect city appearance and road traffic along the way. There are no daily collection time and management; long-term mechanism taking time as node is not formed.

4.4 Policy is not sound; centralized management is short

Although there are kitchen waste recycling requirements in Shanghai, Kitchen Waste Management Method of national level has not yet been formally issued. Government regulations of the city are implemented for a short period; management experience is not enough; supervision system has not been yet completed. Existing disposal enterprises of kitchen waste are difficult to survive independently, relying on local government subsidies; new enterprises are not active in participating in investment. Policy on transportation fee paid by catering organization results in secret discharge and selling by some consumer organizations; supervision and implementation of relevant departments did not keep up with.

\section{Solutions}

5.1 Strictly carry out and improve process of collection and transportation system

The latest Decision on Amendment of 'Management Method for Disposal of Kitchen Waste of Shanghai' from Shanghai Municipal People's Government was passed in the 159th executive meeting of municipal government on December 17, 2012, and implemented from March 1, 2013, of 
which it is stipulated that Shanghai Green and Urban Appearance Bureau is responsible for disposal and management of kitchen waste of the city; Environmental Protection, Industrial and Commercial Bureau, Public Security, Agriculture, Commerce, Food and Drug Supervision, Health, Quality Technical Supervision and other bureaus shall coordinate.

\subsection{Strengthen decomposition of recycling center}

Existing and newly-introduced technologies are various. Due to complexity of composition of kitchen waste, single processing technology is difficult to complete entire stable and efficient processing. The first step is to sort out recycling centers of each county; apart from responsible for storage, arrangement and transport of recycling point in the area under administration, recycling center can increase employment, and coordinate with simple preliminary decomposition and classification of kitchen waste, such as excluding life Garbage, giving priority to sort out type of waste which can be recovered and improving utilization.

For example, if 50t of kitchen wastes are disposed in waste disposal center of Urban Appearance Bureau in Xuhui District for each day, a labor will be increased per ton on average. If 1400t of kitchen wastes generated in Shanghai for each day are all recycled, 1400 posts will be created. Pig feed of 70kg-75kg with value of 1300 yuan will be re-generated from kitchen wastes per ton. If $1400 \mathrm{t}$ of kitchen wastes generated in Shanghai for each day all recycled, 70t of pig feed will be re-generated with production value of more than 80,000 yuan.

5.3 Selection and integration of technology for disposing kitchen wastes

Technology for disposing kitchen wastes is a major research direction for environmental research technology in the world; due to uniqueness of food and beverage habits in China, as well as a variety of food and beverage forms, acclimatized phenomenon will be produced in copy of foreign technology.

A large number of enterprises for disposing kitchen wastes are increased, at the same time, technical capacity of existing enterprises for disposing kitchen wastes need to be integrated and improved. There are six mature processing technologies as follows; each technology is of its own advantages and disadvantages, so technology shall be selected appropriately. At present, aerobic composting process is used in Shanghai; the technology is based on adding special strain, dynamic aerobic digestion, continuous feeding and intermittent discharging; reaction temperature is about $50{ }^{\circ} \mathrm{C}$, that is, composting technology with high digestibility; the process is of higher investment and processing costs.

5.4 Strengthen publicity; improve environmental awareness of the Owner

Vigorously promote harmfulness of kitchen wastes and importance of prevention and control, and enhance awareness of catering industry in pollution control. Give full play to role of propaganda news agencies; mobilize the power of the whole society to promote and protect the common environment and form good atmosphere of everyone's responsibility and participation in environmental protection, so as to contribute to disposal business of kitchen wastes in the city.

\section{Conclusion}

At present, technology and management for kitchen wastes of Shanghai has been in the stage of exploration and progress. At the national level, there are no management policies and technical regulations for kitchen wastes system, and technical policies are in systematic research. Based on investigation of present situation, problems, technical treatment and current management situation of kitchen wastes of Shanghai, disposal measures for local kitchen wastes should be analyzed and summarized, so as to form management method or technical direction of kitchen wastes at the national level. With introduction of a series of favorable national policies and development of technology for recycling kitchen wastes, kitchen wastes will inevitably become a valuable resource with wide prospects. Therefore, environmental protection cause in our country will be thriving. 


\section{Reference}

[1] Du L Z, Chen X, Sun X M, et al. Analysis on Current Situation and Countermeasures of Rural Household Garbage in China[J]. Advanced Materials Research, 2014, 955-959:2640-2643.

[2] Zheng L L, Yong Y, Lin K. Current Status and Countermeasures for Disposition of Hazardous Waste in Chengdu City[J]. Journal of Anhui Agricultural Sciences, 2016.

[3] Li H, Liu G, Cao Y. Levels and environmental impact of PAHs and trace element in fly ash from a miscellaneous solid waste by rotary kiln incinerator, China[J]. Natural Hazards, 2015, 76(2):811-822.

[4] Tao J. On the Industrial City Garbage Disposal Difficulties and Countermeasures[J]. Science \& Technology \& Innovation, 2014.

[5] Zhao Z, Li X, Zhan Y. Situation Analysis and Countermeasures Research on Urban Construction Waste Treatment in Changzhou[J]. Environmental Sanitation Engineering, 2015, 342(1):159-166. 